\title{
Sérgio Miceli e as condições do ofício sociológico e intelectual no Brasil contemporâneo
}

\author{
Henrique da Costa Valério Quagliato ${ }^{1}$
} Eduardo Russo Ramos ${ }^{2}$

$E_{m}$ agosto de 2019, o sociólogo Sérgio Miceli ministrou a conferência de abertura do ano letivo do Programa de Pós-Graduação em Sociologia da Universidade Federal do Paraná ${ }^{4}$. No ensejo de sua visita, organizamos um roteiro de entrevista sobre as condições do ofício sociológico e intelectual no Brasil contemporâneo marcado por novas morfologias do campo intelectual, disputas pelas autoridade cultural e severas investidas contra o conhecimento produzidos pelas Ciências Sociais.

Henrique: Professor, em primeiro lugar, muito obrigado. É uma honra. Formulamos cinco questões para uma breve conversa sobre as condições do ofício sociológico e intelectual no Brasil dos dias atuais. A primeira delas é a seguinte: gostaríamos de saber como você avalia o crescimento da atuação de intelectuais na esfera midiática e do debate público no Brasil contemporâneo. Falamos de figuras como Clóvis de Barros Filho e Leandro Karnal, mas também de Lilia Schwarcz, Debora Diniz e Vladmir Safatle que, de uma maneira ou outra, escrevem para jornais, participam de programas de rádio e televisão - televisão aberta, principalmente. Como você avalia esse fenômeno?

Sérgio Miceli: Essa midiatização dos intelectuais, essa presença midiática... isso já tem um tempo. Acredito que, por causa da polarização existente no Brasil nesses últimos anos, a novidade é que surgiu um grupo de pensadores - nem sei é essa a palavra -, de ideólogos da direita que pertencem a um espectro que, na verdade, é bastante diversificado. Eu tenho

\footnotetext{
1 Aluno Bolsista CAPES do Curso de Doutorado do Programa de Pós-Graduação em Sociologia da UFPR. Contato: henriquequagliato95@gmail.com

2 Aluno Bolsista CAPES do Curso de Doutorado do Programa de Pós-Graduação em Sociologia da UFPR. Contato: ramos.eduardorusso@gmail.com

3 Professor titular do Departamento de Sociologia da USP.

4 A recepção de Pierre Bourdieu no Brasil: circunstâncias e mediadores será publicada integralmente como abertura do primeiro número para o sétimo volume da Revista Sociologias Plurais em janeiro de 2021.
} 
duas alunas fazendo trabalho sobre essa gente. Percebe-se que alguns têm credenciais acadêmicas, outros têm só uma carreira no jornalismo, outros não tem carreira no jornalismo ou nem credencial acadêmica, construindo uma carreira na mídia eletrônica, alguns vieram, ainda da televisão. Muitos não têm formação intelectual nenhuma e são estações repetidoras de pensamento conservador estrangeiro. E você tem também muitos intelectuais acadêmicos - como a Lilia, Vladmir, André Singer etc. - que são a contraparte desse embate. Eu acho que faz todo sentido que, como intelectuais públicos, construam esse debate. Alguns debatem melhor. Outros, pior. Mas eu acredito que isso não é fazer sociologia, nem é uma atividade intelectual que tenha uma autonomia reflexiva. Acho que isso é uma atividade prática, um embate político - plenamente válido e justificado. Mas não acho que, do ponto de vista intelectual, seja tão instigante assim.

Eduardo: Professor, voltando à questão da sociologia dos intelectuais no Brasil, você se destacou no cenário intelectual nacional por conta da contribuição tanto analítica quanto teórico-metodológica de Intelectuais e Classe dirigente no Brasil (1920-1945), publicado em 1979. Passados quarenta anos, a sociologia dos intelectuais no Brasil recebeu diversas contribuições a partir de enquadramentos distintos. Passamos de estudos voltados para as relações entre intelectuais, partidos, classes e Estado para estudos que colocam uma ênfase mais no produto gerado por intelectuais, na produção vinculada a grupos culturais etc. - um bom exemplo, na década 1950 e 1960, são as produções do Centro Popular de Cultura da União Nacional de Estudantes - e, também, esses projetos de intervenção pública que figuras intelectuais levam a campo. Qual é a sua avaliação desse itinerário da sociologia dos intelectuais no Brasil? Como você entende a relevância dos estudos sobre intelectuais para o tempo do Brasil de hoje?

Sérgio Miceli: Eu vou tentar responder de uma forma quase caricatural para que fique mais claro. Acredito que a grande mudança - o efeito de grande rotação morfológica na dinâmica do campo intelectual - tem a ver com o embate crescente das pretensões de legitimidade entre academia e a indústria cultural. Esse é um embate muito esclarecedor e, inclusive, tem muito a ver com a primeira pergunta feita. Se você realizar uma análise criteriosa das posturas da imprensa brasileira - Globo, Folha de São Paulo, Estado de São 
Paulo etc. - sobre questões tão controversas como a Universidade pública e coisas do tipo, você perceberá um embate que, aparentemente, gira em torno dessas questões, mas que, no fundo, é um reclamo de autoridade cultural por parte da mídia - enfrentando os representantes do pensamento acadêmico. Por exemplo, sobre a tentativa de depreciar a Universidade pública, eu acredito que, tão importante quanto a tentativa de discussão e crítica, é a pergunta: em nome do quê? Qual é o reclamo de autoridade cultural dessa voz que fala sobre a Universidade pública? Na maioria dos países europeus, a mídia já passou desse momento - e, na verdade, se alimenta muito das vozes dos intelectuais acadêmicos para dar opiniões sobre diversos assuntos sobre os quais jornalistas não entendem muito ou não cobrem da mesma forma. Então, nós estamos tendo no Brasil essa transformação que já tem anos e é muito importante. Agora, por que os alvos desse debate são a Universidade pública, o dinheiro público, financiamento, o ensino pago etc.? A leitura mais fácil é dizer "essa gente está defendendo os interesses do ensino particular". Essa resposta tem seu fundo de verdade. Se montou, como vocês sabem, um sistema de agências, de organismos, de ONGs em defesa do ensino particular - isso é verdade. Mas eu acredito que existe, digamos assim, uma reformatação, uma nova morfologia do campo de produção cultural. Nesse mercado de bens simbólicos - utilizando o termo que o Bourdieu usou há quarenta anos - existe um protagonismo crescente dessa mídia. Não falo só da mídia impressa. Falo também da mídia eletrônica, da internet, das redes. Esse protagonismo crescente carrega sempre um embate em torno da autoridade cultural - porque é em torno da autoridade cultural que falam desde Olavo de Carvalho até Florestan Fernandes. Olavo de Carvalho não quer só falar as abobrinhas que fala. Ele está reivindicando uma autoridade, um poder de falar - “qual é a minha autoridade pra falar?". Agora, por que essa polarização tem sido crescente? Peguemos as Universidades Federais e os ataques proferidos contra elas. A situação se torna um empasse monumental para o Governo Federal. Por que? Eu não acho que será tão simples desviar desse tipo de questão, porque as Universidades Federais, em muitos estados, são instâncias decisivas econômica e culturalmente. A elite desses estados, os governantes desses estados não irão abrir mão dessas Universidades. Então temos aí um grande problema. Digamos assim: a morfologia do campo de produção cultural se tornou muito mais complexa em relação ao momento em que eu fiz o trabalho. Ali, nós estávamos observando os germes, os primórdios de um 
processo de institucionalização com o foco na criação de centros de pesquisa, de programas, de sítios de reflexão dentro do mundo intelectual. Hoje nós temos uma morfologia muito mais diversificada, com muito mais atores, muito mais protagonistas todos tendendo a esse embate. Acredito que essa é uma transformação importante no âmbito da mídia e sua relação com intelectuais. Houve uma transformação grande do sistema intelectual, do sistema acadêmico. Construiu-se um redimensionamento, uma amplificação. Eu dei os exemplos das Federais porque, por coincidência, nos dois últimos anos, eu tenho ido há várias Federais e é impressionante o que aconteceu. Você tem grupos novos de professores jovens que fazem trabalhos muito interessantes, consistentes, e que não estão mais referidos só à dominância Rio-São Paulo. As coisas se complicaram em termos das relações internas do mundo intelectual e do mundo acadêmico. Se trata, como eu disse, de uma transformação morfológica que não existia na época de meu estudo. Quando eu fiz o trabalho sobre a história das Ciências Sociais, nosso dilema era: "Mas que estados nós vamos observar? O que é importante fora do eixo Rio-São Paulo? Qual é a produção? Gilberto Freyre em Recife; em Minas tinha o pessoal da Ciência Política”. Hoje, seria um outro tipo de desafio porque a peneira tem de peneirar muito mais agentes. Muito mais focos produtivos. Dessa forma, acredito que, para pensar bem o problema, teríamos de pensá-lo em termos da conjunção de circunstâncias através das quais o campo cultural foi se transformando - foi ganhando carne, ossatura e vertebração diferente. Nos anos 1950 e 196o havia um embate: o Livro do Marcelo Ridenti5 mostra que o Partido Comunista tinha uma rede de organismos - de imprensa etc. Assim as conjunturas vão mudando. Eu acredito que estamos vivendo isso. Por que a mídia tem tanta importância no Brasil? Porque ela sempre teve uma função, digamos assim, "paraescolar", "parapedagógica”. Porque, como aqui o sistema de alfabetização demorou uma enormidade para alcançar pisos decentes, então a mídia pôde exercer essas funções pedagógicas complementares ao sistema de ensino. Isso é impensável na França. Na França, a televisão não tem nenhum protagonismo na vida cultural como tem no Brasil. Tem uma presença - a imprensa também -, mas não é como no Brasil. Não ocupa esse espaço. Então, é sempre bom tentarmos construir um panorama maior para tentar ver essas transformações, acredito

5 Trata-se de O fantasma da revolução brasileira, publicado por Ridenti em 1993. 
eu. Também é importante, claro, considerar que o trabalho intelectual está muito mais profissionalizado e, por isso, depende muito menos de origem de classe - um elemento que era muito importante no meu argumento.

Eduardo: Aproveitando a menção ao Instituto de Estudos Econômicos, Sociais e Políticos de São Paulo (Idesp) feita durante a aula inaugural, sua passagem por lá e o financiamento para pesquisa oferecido pela organização, podemos formular a próxima questão que muito nos interessa. Parte da sua carreira profissional se cruza com a existência de associações e institutos que promoveram pesquisa na área das Ciências Sociais com apoio de verbas alternativas àquelas oferecidas para as universidades públicas - sua passagem pelo Idesp é um exemplo disso. Em entrevista ao projeto Memória das Ciências Sociais no Brasil, ${ }^{6}$ em 2012, você descreveu a participação de pesquisadores dentro dessas associações como uma tendência objetiva - uma saída para os entraves postos as universidades públicas naquele momento. A nossa pergunta é: frente aos recentes contingenciamentos e um cenário de precarização da Universidade pública no Brasil, quais são as condições sociais de possibilidade de pesquisa no país?

Sérgio Miceli: Olha, eu acho que, se eles conseguirem levar à cabo o que estão intentando, vai ficar difícil. Eu estava até falando outro dia com os amigos e eu acho que vamos ter de voltar ao período de fazermos grupos de estudo. Vai ser uma coisa recessiva. Caso essas condições que se apresentam sejam concretizadas - me refiro ao corte de bolsas, dinheiro de financiamento de pesquisas, editais etc. - vamos viver um período sombrio. Mas eu acredito que não devemos nos desesperar a respeito do período sombrio, pois houve uma produção intelectual importante no período da ditadura - não apenas nas Ciências Sociais, mas no Cinema, Teatro, Música... Não é um jogo de soma-zero. Agora, a melhor resposta que se pode dar é trabalhar com o que é possível. O que é mais ameaçador no que nós fazemos é justamente o nosso trabalho, não é ficar berrando. Esse negócio de "vamos resistir"... Resistir é trabalhar.

6 A entrevista completa está publicada no canal da Faculdade Getúlio Vargas (FGV), no Youtube. Entrevista com Sergio Miceli (10/o2/2012) <https://www.youtube.com/watch?v=7OjFO7bGqo\&feature=emb_title>. Acesso em: 10 de outubro de 2019 . 
Eduardo: Mas você enxerga alguma forma de financiamento alternativo na atualidade?

Sérgio Miceli: Mas quais financiamentos alternativos? As fundações privadas norteamericanas tem, hoje, agendas distantes das Ciências Sociais. São agendas ligadas a imposição de políticas públicas na área do direito, relações de gênero, direitos humanos. Essas são propostas muito sanitizadas, muito higienizadas e que não contemplam a diversidade temática que as Ciências Sociais têm hoje. Então, acho difícil que essas fundações voltem a se relacionar com a nossa área. Vocês se lembram: o Idesp, o Centro Brasileiro de Análise e Planejamento (CEBRAP) e a própria Associação Nacional de PósGraduação e Pesquisa em Ciências Sociais (Anpocs) tiveram um papel importante na relação com esse tipo de financiamento. A Fundação Ford concedeu um milhão de dólares para a Anpocs a fim se despedir do financiamento da entidade há alguns anos. Desde a fundação da entidade até essa doação de um milhão de dólares, se financiava, praticamente, toda a associação. Isso não é mais possível. Tanto assim que as associações estão dependendo cada vez mais de contribuições dos próprios sócios, dos profissionais associados. Eu acredito que, se, os cortes forem levados à cabo e não houver financiamento das organizações privadas, visto que não temos tem mecenato privado no Brasil, nós estaremos mal.

Henrique: Se pensarmos em fundações nacionais que estão, por exemplo, ligadas a promoção da cultura, as Ciências Sociais não conseguiriam se voltar também para esses espaços?

Sérgio Miceli: Me vêm à cabeça o Instituto Moreira Salles, Instituto Cultural Itaú, mas, em especial o Serviço Social do Comércio (SESC). O SESC, em São Paulo, oferece muito espaço para as Ciências Sociais em relação ao financiamento de eventos, conferências, vinda de professores visitantes - a entidade vem fazendo isso há muitos anos. Por quê? Porque uma porção de gerentes do SESC são cientistas sociais. São pessoas que fizeram doutorado dentro das Ciências Sociais, são agentes com agenda nas Humanidades. Agora, o Instituto Moreira Salles é muito voltado pra fotografia, para nichos que não têm muito espaço para nossa área. A família Moreira Salles criou um espaço de investigação 
científica apenas para as ciências exatas - o Instituto Serrapilheira - que está funcionando no Rio de Janeiro e está dando dinheiro para as ciências exatas fazendo editais de concursos. Há, nesse sentido, um esboço de mecenato privado para atividade científica, mas, para as Humanidades, eu acredito que a coisa não está muito boa.

Henrique: Aproveitando o gancho da relação das Ciências Sociais com a agenda pública e com o que está acontecendo no país, essa é uma pergunta mais para dentro da Sociologia. A discussão sobre objetividade na investigação sociológica está presente na disciplina desde seu início. Durkheim e Weber trataram dela de uma maneira privilegiada e, na segunda metade no século XX, ela também tem um papel importante - mesmo para o próprio Pierre Bourdieu. Contudo, o clima do país e a recente eleição do presidente Jair Bolsonaro trazem um clima anticientífico, anti-intelectual paro debate público. Em meio a esse quadro, a Sociologia e as Humanidades têm de lidar com o estigma de serem vistas apenas como produções ideológicas e doutrinárias. A questão é a seguinte: como a Sociologia pode se afirmar como forma de construção de conhecimento para o Brasil, para o público, sem perder a nuance dos debates construídos recentemente sobre a questão da objetividade?

Sérgio Miceli: O problema da objetividade, sejamos sinceros, sempre foi um problema que deve ser entendido cum grano salis. É preciso ter cautela com essa discussão. A Sociologia não pode ter uma pretensão de tornar-se uma ciência completamente objetiva, porque isso é impossivel. Você, em qualquer trabalho que você esteja fazendo, está investindo a sua experiência. Ao investir a sua experiência, você está investindo a sua perspectiva, um ponto de vista - e isso não te dá uma possibilidade de voo de pássaro sobre todo o ambiente da tua investigação. O foco de seu estudo tem a ver com a tua experiência. Não há saída para isso. Então, a discussão sobre a objetividade se coloca, na verdade, na maneira pela qual você lida com a sua própria subjetividade - que você deve enquadrar através de uma atitude mais reflexiva. Eu entendo que a discussão que sobre objetividade em termos puros é ociosa. Agora, em termos de uma postura mais reflexiva, aí eu acredito que seja algo mais produtivo. 
Henrique: Entendo. Mas esse é o caso quando são sociólogos falando com sociólogos. Quando o sociólogo tem de falar para a esfera pública e, portanto, requisitar uma espécie de autoridade científica, como tratar a questão da objetividade científica?

Sérgio Miceli: Como ela vem sendo tratada. Veja todos os artigos que tem saído... Renato Ortiz escreveu semana passada na Folha de São Paulo7. Todos estão reproduzindo o receituário clássico - afirmando que trabalhamos com dados empíricos e com métodos que são contraditados. Para as respostas, é um cardápio que não tem muita saída. Porém, o cardápio não é o que está em jogo. O que está em jogo é a tentativa de desautorização, de desqualificação. Não dá pra jogar o jogo nos termos que em que eles desejam. É necessário mudar. Só se pode jogar o jogo com o seu manancial, com os seus recursos. E os únicos recursos que você tem são os recursos intelectuais. Então, de uma certa maneira, nós estamos num mato, sem cachorros. Mas, pelo menos, o mato a gente conhece! (risos).

Henrique: Caminhando para o final da entrevista, trouxemos uma pergunta que é mais aberta - ligada as nossas próprias dúvidas como estudantes de mestrado na área da Sociologia. Você faz parte de uma geração de sociólogos que se formou durante a Ditadura Militar - um tempo de fechamento político e tons autoritários. E, enquanto alguns desses tons autoritários começam a retornar no Brasil como um novo fechamento político e o ataque às instituições públicas de conhecimento que é enunciado descaradamente, também surge uma nova geração de sociólogos. A questão é: que conselhos você pode oferecer novas gerações de acadêmicos que desejam se tornar sociólogo e sociólogas em um tempo de fechamento político como esse?

Sergio Miceli: A verdade é que se conselho rendesse, nós não pararíamos de oferecê-los (risos). Mas, posta a questão nesse termos, eu acredito que existe um movimento estrutural que não tem só a ver com a Sociologia. Vocês estão enfrentando uma situação no mercado de trabalho que se mostra muito tempestuosa, muito difícil. Eu vou simplificar pra ficar bem claro o que eu quero dizer. Hoje, a possibilidade de emprego fixo e uma

7 Miceli se refere ao texto Verdade e Mentiras, publicado por Ortiz no jornal Folha de São Paulo em agosto de 2019. <https://www1.folha.uol.com.br/opiniao/2019/o8/verdades-e-mentiras.shtml>. Acesso em: 10 de outubro de 2019 . 
carreira existe para pouquíssimos em relação ao número total de candidatos. Quando se faz um concurso hoje, se fosse realizado um sorteio no lugar prova, o resultado não seria muito diferente. Se você tem 6o candidatos buscando uma única vaga, é claro que existem, pelo menos, 12 bem qualificados. Então, pode-se fazer um sorteio que não haverá muita diferença. Eu penso que há uma situação estrutural que não se relaciona apenas com cientistas sociais. Tem a ver com, vamos dizer, as novas balizas de operação de um mercado de trabalho com poucas possibilidades de emprego e remuneração fixos; e poucas probabilidades de seguro, de aposentadoria - benefícios e expectativas em relação aos quais minha geração se formou. Por que eu saí da FGV e fui pra Universidade de São Paulo (USP)? Porque eu iria ter aposentadoria integral. Se não, eu ficaria onde estava, onde eu tinha um melhor salário. Creio que esse seja um elemento que não depende dos cientistas sociais. Não tem a ver só com as Ciências Sociais e isso não está afetando só os cientistas sociais. Vemos um complexo problema estrutural do mercado de emprego. Na Itália, por exemplo, uma grande porcentagem das pessoas que se separam, voltam pra casa dos pais ou vivem das pensões dos avós - li sobre isso recentemente. Há uma questão estrutural aí e nós teremos de aprender como lidar com isso. Eu acredito que, para vocês, é uma situação de desafio e incerteza. É uma coisa que não é brasileira, somente. Quando abrese uma vaga para um posto no Centre National de la Recherche Scientifique (CNRS), na França, existe uma concorrência de cento e sessenta candidatos para uma vaga. O que essas pessoas irão fazer? Só tem um posto. E os outros? Está havendo uma situação semelhante ao que Frtiz Ringer ${ }^{8}$ descreveu na Alemanha dos anos 1920. Está havendo uma inflação de credenciamento, de diplomas, sem uma correspondente possibilidade de atendimento dessas expectativas. E esse fosso está se ampliando, então... Eu não acho que sejam conselhos, mas vocês vão lidar com uma situação concreta em que há de se fazer a pergunta: onde é que vocês poderão exercer essa competência que vocês adquirem? Farão conforme as possibilidades de emprego - na universidade, na mídia, na televisão, nas redes sociais, em empresas de pesquisas. Eu não sei. Dos doutores que nós formamos na USP ou em qualquer lugar, é um número ínfimo que consegue se reproduzir no sistema acadêmico. Nós temos um problema aqui que não tem só a ver com as Ciências Sociais. O buraco é

8 Miceli refere-se a $O$ declínio dos mandarins alemães - a Comunidade Acadêmica Alemã, 189o-1933, publicado por Ringer em 1969. 
mais embaixo. Vocês sabem disso.

Henrique: Além da condição financeira, nós pensamos também na condição temática. De que, talvez, seja, como você já disse, uma higienização das temáticas de pesquisa nas próprias Ciências Sociais por conta dessa necessidade de ocupar outros espaços...

Sergio Miceli: Isso já começou e já tem muito tempo. O local para a resistência a essa tendência era o espaço acadêmico porque, se você tem uma carreira protegida, um salário garantido, você tem mais jogo, mais área de manobra e não está dependendo da sua produção sob encomenda para um mecenas ou para uma fundação. Agora, eu não sou tão pessimista a respeito de trabalho sob encomenda. Eu acho que se pode fazer coisas muito boas em trabalhos sob encomenda. É contraditório isso, mas isso sempre foi parte da produção cultural. Desde a produção de ópera até todo o restante. A encomenda não deve ser vivida como uma coisa apenas constrangedora. $\grave{A}$ despeito da sanitização e higienização, da departamentalização e da delimitação de agendas na história do financiamento de pesquisas na área das Ciências Sociais, houve trabalho de qualidade realizados com dinheiro das fundações privadas. Então as coisas são muito contraditórias. Há muita frincha. É fácil averiguar as condições da imposição. O que é mais difícil é oxigenar as condições de resposta, digamos assim. Ventilar a condição de resposta. É mais fácil identificar onde estão nos questionando e nos constrangendo do que fazer boa invenção ventilada e oxigenada para uma resposta mais contundente, mais criativa. A atividade intelectual, e em Sociologia, inclusive, tem muito a ver com invenção e a criatividade. Há um componente artístico na atividade intelectual. E é preciso prestar atenção nisso, porque uma medida do teu desempenho é a tua expressividade. Afinal, sem expressividade, o que você vai fazer? E a expressividade não tem figurino. $\hat{E}$ a tua experiência que vai produzir uma forma expressiva. Ainda bem, não?! 